\title{
Consumer-Led Power Management in Local Distribution Networks
}

\author{
Sima Davarzani, Ioana Pisica, Gareth A. Taylor \\ Institute of Energy Futures, Smart Power Networks \\ Brunel University London, UK \\ Sima.davarzani@brunel.ac.uk
}

\begin{abstract}
The centralised electricity generation system is now moving towards localised and distributed energy sources. The penetration of new renewable energies along with the introduction of new loads to the power grid cause several challenges in the future of distribution networks. This paper aims to investigate how effectively local energy community's engagement can contribute in managing the demand-supply balance in distribution networks. For this purpose, an advanced demand response scheme is introduced where households within a local energy community can collaborate with each other to reduce the total energy demand. The proposed scheme is implemented using a multi agent system framework and in a modified IEEE 69 bus radial network. The simulation results demonstrated that the overall community independency to the power grid can significantly decrease specifically during $P V$ generation period.
\end{abstract}

Keywords-- distributed generation, demand response, distribution network, local community, multi agent system

\section{INTRODUCTION}

The recent studies have demonstrated the role of demand response (DR) in controlling the power flow constraints in distribution networks [1]. The contribution of DR can eventually result in more flattened demand profiles by reforming the consumers' consumption patterns. In spite of voluntary price-based DR participation and feed-in tariff schemes, if critical issues occur when the available responsiveness loads can no longer be obtained, direct approaches of demand reduction are then required. On the other hand, increased distributed generation installed at household level enables DR to be evolved further to maintain supplydemand balance in a real-time environment [2]. In this way, distributed flexible generation and load resources can be directly controlled by their owners to improve the reliability and security of distribution networks [3].

This paper aims to provide a framework for Local Community Demand Response (LCDR) from residential households. The proposed advanced DR aims to mitigate the constraints in the distribution network when the system is under stress condition. In the proposed framework, consumers are incentivised to engage in DR programmes through two complimentary incentives: feed-in-tariffs and a novel reward for local utilisation or generation resources. The former one refers to the payment made to households for generating and selling electricity at community level from local renewable sources.

The proposed methodology is implemented in a Multi Agent System (MAS) structure where each household is defined as an agent. A group of households within each Low Voltage (LV) feeder in the network connects to a Local Community Aggregator Agent (LCAA). These agents can communicate with each other to create a local community. If any emergency condition occurs, the required demand curtailment or purchased generation are sent to the households in that community from the LCAA. Accordingly, households decide about their consumption behavior with the view to minimise its dependency to the external grid. Their updated load profiles as well as available extra generation is submitted to LCAA. The pre-determined reward will be allocated to the participants based on their participation. Moreover, LCAA runs a merit-order procedure to maximise local usage of renewable generation.

\section{PROPOSED FRAMEWORK}

This section describes the proposed framework to implement LCDR for households using MAS. The general framework overview is presented in Fig. 1. The aim of this paper is to investigate the role of energy communities in managing the distribution network constraints. Hence, the platform consists of two main types of agents: Household Agent (HA) and LCAA. The system operator is not discussed here. However, its role has been modelled through a DR event signal which is sent to LCAA during system stress conditions. Households only communicate with their relevant LCAA.

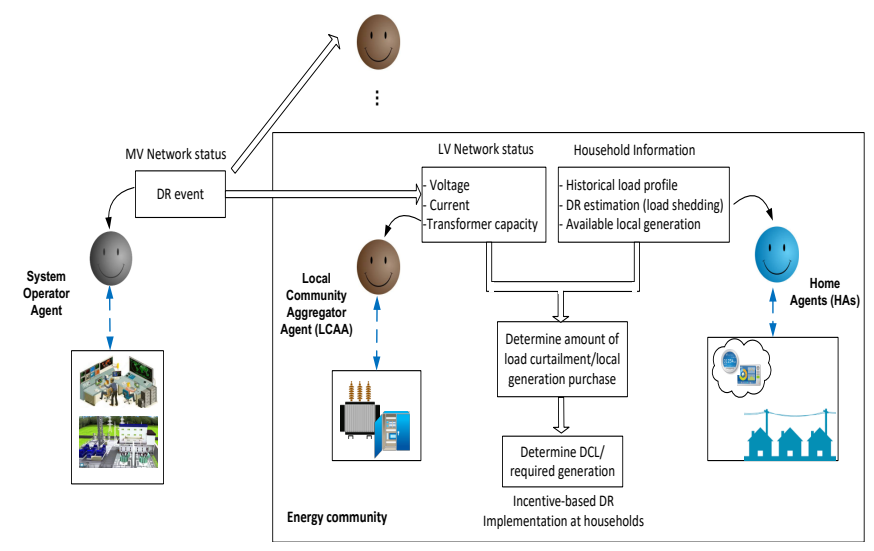

Fig. 1. Proposed MAS overview 
The proposed LCDR scheme is a voluntary and incentivebased DR where the incentives are determined in advance. Therefore, the energy supplier has not been considered in the MAS framework. It is worth to clarify that it is assumed that some households can produce local power through PV panel installed in their roof-top.

\section{METHODOLOGY}

This section describes the mathematical formulations for modelling each agent's tasks and goals. The overall DR control mechanism aims to enable the implementation of an incentivebased DR called local community DR (LCDR) in real-time environment. During emergency conditions, e.g., system stress conditions at either LV or MV network, the feeder agent sends a DR event to its associated households. The DR signal contains required Demand Curtailment Level (DCL) along with duration of DR event. Households can participate in LCDR scheme based on two responsiveness loads: Load shedding and local (on-site) generation.

The methodology for each agent in order to achieve its goals is detailed in the following.

\section{A. Home Agent}

The aim of each HA is to maximise its financial incentives which can provide by either minimising its dependency or by selling the extra local generation to the power grid.

The former can be yielded through two opportunities. Firstly, HAs can supply their power consumptions from the maximum PV generation, e.g., shifting their controllable appliances to peak-time PV generation. Therefore, the total electricity bill reduces. It is clear that this is only possible for households that are equipped with PV. This is expressed as:

$$
\Delta_{\mathrm{h}, \mathrm{t}}^{\mathrm{l}, \mathrm{G}}=\mathrm{G}_{\mathrm{h}, \mathrm{t}}^{\max }-\mathrm{l}_{\mathrm{c}, \mathrm{h}, \mathrm{t}}, \forall \mathrm{c} \in \mathrm{C}, \mathrm{h} \in \mathrm{H}, \mathrm{t} \in \mathrm{T}
$$

where, $\Delta_{\mathbf{h}, \mathbf{t}}^{\mathbf{l}, \mathbf{t}}$ denotes the difference between the total preliminary load of household $h\left(\mathbf{l}_{\mathbf{h}, \mathbf{t}}\right)$ and the maximum PV generation $\left(\mathbf{G}_{\mathbf{h}, \mathbf{t}}\right)$ at timeslot $\mathbf{t}$. A negative value of $\Delta_{\mathbf{h}, \mathbf{t}}^{\mathbf{l}, \mathbf{G}}$ states the total required demand $\left(\mathbf{D}_{\mathbf{h}, \mathbf{t}}^{\mathbf{W R}}\right)$ at timeslot $\mathrm{t}$ as:

$$
\begin{gathered}
\mathrm{D}_{\mathrm{h}, \mathrm{t}}^{\mathrm{WR}}=\left|\Delta_{\mathrm{h}, \mathrm{t}}^{\mathrm{l}, \mathrm{G}}\right| \\
, \forall \Delta_{\mathrm{h}, \mathrm{t}}^{\mathrm{l}, \mathrm{G}}<0, \quad \mathrm{~h} \in \mathrm{H}, \mathrm{t} \in \mathrm{T}
\end{gathered}
$$

From equation (2), it can be clearly seen that in households without $\mathrm{PV}_{\mathbf{h}, \mathbf{t}}^{\mathrm{WR}}=\mathbf{l}_{\mathbf{h}, \mathbf{t}}$.

Secondly, HAs can participate in load shedding DR where they can reduce their total energy utilisation according to the received DCL signal. A DCL is sent to HAs at each time-slot $t$ for decision-making at the next timeslot $\mathrm{t}+1$. at each local community, HAs are rewarded based on their participation in demand reduction. The maximum available DR provision from each household $\mathrm{h}$ at timeslot $\mathrm{t}$ is:

$$
\mathrm{DR}_{\mathrm{h}, \mathrm{t}}^{\max }=\left\{\begin{array}{cc}
\mathrm{DCL}_{\mathrm{t}}-\mathrm{D}_{\mathrm{h}, \mathrm{t}}^{\mathrm{WR}} & , \forall \mathrm{DCL}_{\mathrm{t}} \geq \mathrm{D}_{\mathrm{h}, \mathrm{t}}^{\mathrm{WR}}, \Delta_{\mathrm{h}, \mathrm{t}}^{\mathrm{l}, \mathrm{G}}<0 \\
\mathrm{D}_{\mathrm{h}, \mathrm{t}}^{\mathrm{WR}}-\mathrm{l}_{\mathrm{h}, \mathrm{t}}^{\mathrm{LD} \text { max }} & , \forall \mathrm{DCL}_{\mathrm{t}}<\mathrm{D}_{\mathrm{h}, \mathrm{t}}^{\mathrm{WR}}, \Delta_{\mathrm{h}, \mathrm{t}}^{\mathrm{l}, \mathrm{G}}<0 \\
0 & , \forall \Delta_{\mathrm{h}, \mathrm{t}}^{\mathrm{l}} \geq 0
\end{array}\right.
$$

$\mathbf{l}_{\mathbf{h}, \mathrm{t}}^{\text {LD,max }}$ is the maximum load that can be lessened at timeslot $t$. The participation of HAs in LCDR upon receiving a DR event signal is optional. The actual amount of load reduction relies on the satisfaction factor $\left(\boldsymbol{\delta}_{\mathbf{h}}\right)$ of each HA which consisted of its motivation and attitudes towards participating in DR schemes. Therefore, the total demand required from the grid after implementing DR $\left(\mathbf{D}_{\mathbf{h}, \mathbf{t}}^{\mathbf{R}}\right)$ for each HA, is:

$$
\mathrm{D}_{\mathrm{h}, \mathrm{t}}^{\mathrm{R}}=\mathrm{D}_{\mathrm{h}, \mathrm{t}}^{\mathrm{WR}}-\left(\delta_{\mathrm{h}} * \mathrm{DR}_{\mathrm{h}, \mathrm{t}}^{\max }\right), \forall \mathrm{h} \in \mathrm{H}, \mathrm{t} \in \mathrm{T}
$$

where, $\delta_{\mathrm{h}}$ is calculated as:

$$
\delta_{\mathrm{h}}=\mathrm{A}_{\mathrm{h}} * \mathrm{FM}_{\mathrm{h}}
$$

$\mathbf{A}_{\mathbf{h}}$ and $\mathbf{F M}_{\mathbf{h}}$ are the willingness and financial motivation of each household $h$ in DR participation. At each timeslot $t$, HAs send the values of $\mathbf{D}_{\mathbf{h}, \mathbf{t}}^{\mathbf{R}}$ and $\mathbf{G}_{\mathbf{h}, \mathbf{t}}^{\mathbf{T G}}$ to their associated LCAA.

All HAs, with/without PV, are eligible for this programme. However, HAs with PV can curtailed their demands if $\Delta_{\mathbf{h}, \mathbf{t}}^{\mathbf{l , G}}$ in equation (1) is negative. In other words, if there is still demand that is needed to be supplied from the grid after PV utilisation. Otherwise, they can provide their extra generation to the grid and benefit from feed-in-tariff. In this case, the responsiveness loads are on-site generations and the feed-in-tariff, defined by energy suppliers, is allocated to them. According to equation (1), at each timeslot t, the extra available local generation from household $\mathrm{h}\left(\mathbf{G}_{\mathbf{h}, \mathbf{t}}^{\mathbf{T G}}\right)$ is the positive value of $\Delta_{\mathbf{h}, \mathbf{t}}^{\mathbf{l}, \mathbf{G}}$ as:

$$
\begin{gathered}
\mathrm{G}_{\mathrm{h}, \mathrm{t}}^{\mathrm{TG}}=\Delta_{\mathrm{h}, \mathrm{t}}^{\mathrm{l,G}} \\
, \forall \mathrm{D}_{\mathrm{h}, \mathrm{t}}^{\mathrm{WR}} \geq 0, \quad \mathrm{~h} \in \mathrm{H}, \mathrm{t} \in \mathrm{T}
\end{gathered}
$$

Equation (6) indicates that at $\Delta_{\mathbf{h}, \mathbf{t}}^{\mathbf{I}, \mathbf{G}}>\mathbf{0}$, the households experience their maximum power independency to the grid.

\section{B. Feeder Agent}

LCAA aims to manage the network constraints at its feeder or to response to any DR event which is sent from network operators. LCAA collaborates with HAs in a local community to reduce the needs of the community electricity to the grid. As explained previously, this is achieved by either allocating DCL to HAs in order to curtail their consumptions or purchasing generation from them. A power flow analysis is applied to determine the network status. The methodology introduced in $[4,5]$ is used in order to calculate the total required DR $\mathbf{D C L}_{\mathbf{c o , t}}^{\text {req }}$ for community co. The allocation of DCL to each HA is based on the DR potential of each cluster of households using clustering technique and merit-order.

At each timeslot $t$, LCAA updates its information about $\mathbf{G}_{\mathbf{h}, \mathbf{t}}^{\mathbf{R}}$ and $\mathbf{D}_{\mathbf{h}, \mathbf{t}}^{\mathbf{R}}$ from all its connected HAs as:

$$
\begin{gathered}
\mathrm{D}_{c o, \mathrm{t}}^{\mathrm{req}}=\sum_{\mathrm{h}} \mathrm{D}_{\mathrm{h}, \mathrm{t}}^{\mathrm{R}} \\
\mathrm{G}_{c o, \mathrm{t}}^{\mathrm{ava}}=\sum_{\mathrm{h}} \mathrm{G}_{\mathrm{h}, \mathrm{t}}^{\mathrm{TG}} \\
, \forall c o \in C O, \mathrm{~h} \in \mathrm{H}, \mathrm{t} \in \mathrm{T}
\end{gathered}
$$

where, $\mathbf{D}_{\mathbf{l v}, \mathbf{t}}^{\text {req }}$ and $\mathbf{G}_{\mathbf{l v}, \mathbf{t}}^{\text {ava }}$ indicate the aggregated demand and available generation from all HAs at timeslot $t$. Therefore, $\mathbf{D R}_{\mathbf{l v , t}}^{\mathbf{r e q}}$ is calculated as: 


$$
\mathrm{DR}_{\mathrm{co}, \mathrm{t}}^{\mathrm{req}}=\mathrm{TC}_{\mathrm{co}, \mathrm{t}}^{\mathrm{max}}-\mathrm{D}_{\mathrm{co}, \mathrm{t}}^{\mathrm{req}}, \forall \mathrm{co} \in \mathrm{CO}, \mathrm{t} \in \mathrm{T}
$$

If $\mathbf{D}_{\mathbf{c o , t}}^{\text {req }}>\mathbf{0}$, LCAA needs to buy generation from available sources resulting in the maximum power independency from the grid. The total quantity of required generation at community co in order to meet the total demand at timeslot $\mathrm{t}\left(\Delta_{\mathbf{c o ,}, \mathbf{t}}^{\mathbf{l , G}}\right)$ is calculated as:

$$
\Delta_{\text {co,t }}^{\mathrm{I}, \mathbf{G}}=\mathbf{G}_{\mathbf{h}, \mathrm{t}}^{\mathrm{TG}}-\mathbf{D}_{\mathbf{c o , t}}^{\mathrm{req}}
$$

where, $\mathbf{G}_{\mathbf{l v}, \mathbf{t}}^{\mathbf{b u y}}$ is the amount of energy that needs to be purchased at timeslot $\mathrm{t}\left(\Delta_{\mathbf{c o ,}, \mathbf{t}}^{\mathbf{l , G}}\right)$ from all HAs () is:

$$
\mathbf{G}_{\text {co,t }}^{\text {buy }}= \begin{cases}\Delta_{\text {co,t }}^{\mathrm{l}, \mathbf{G}}, & \Delta_{\text {co,t }}^{\mathrm{l}, \mathrm{G}}>\mathbf{0} \\ \mathbf{G}_{\mathrm{h}, \mathrm{t}}^{\mathrm{TG}} & \Delta_{\text {co,t }}^{\mathrm{l}, \mathrm{G}} \leq \mathbf{0}\end{cases}
$$

A merit-order is applied to select the HAs and also to determine the amount of purchased energy $\left(\mathbf{G}_{\mathbf{h}, \mathbf{t}}^{\text {buy }}\right)$ from them. The merit-order chose the HAs according to highest local generation availabilities within each local community. It is assumed that all consumers at al communities are under the same feed-in-tariff rate.

\section{Overall DR Control}

The overall DR control algorithm is presented in Fig 2. At each timeslot $t$, each agent updates its information. If any DR event occurs, LCAA calculates the DCL and sends it to all HAs within the community as a DR event signal. HAs then decide about their power consumption behavior, e.g., reducing electricity consumption. Afterwards, they response to the LCAA by providing it with their updated load profiles and available energy sources (if they have any) for the next timeslot $t+1$. In case of any further DR provision, LCAA determines the selected HAs and supply the required demand by maximimg the usage of local generation.

At the end of DR event, a pre-determined incentive is assigned to each community where it further shares among the participants. Moreover, an extra incentive is also allocated to the community with highest load reduction among all communities in the network.

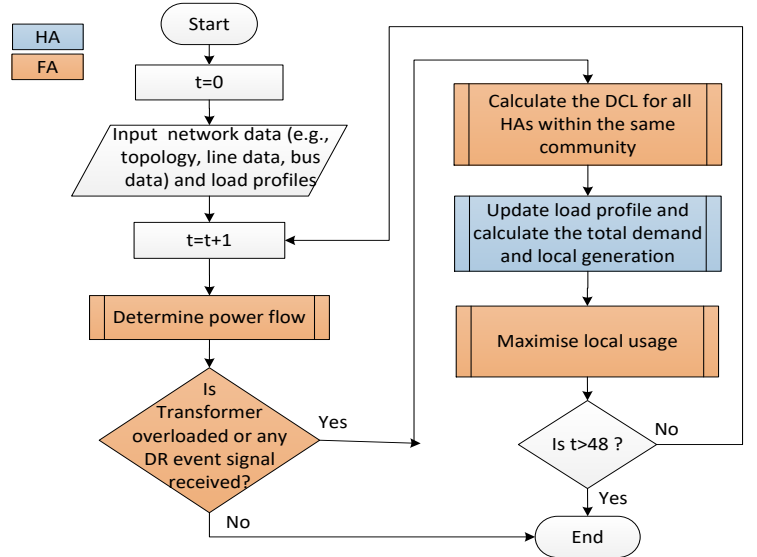

Fig. 2. Overall DR control mechanism flowchart for implementing the proposed LCDR

\section{SimULATION MODELLING AND SETUP}

In order to validate the proposed DR control mechanism, a modified IEEE 69-bus $12.66 \mathrm{kV}$ radial distribution network consisting of $8 \mathrm{MV}$ and $48 \mathrm{LV}$ feeders is used as the test network. Each LV feeder is fed from a $12.6 / 0.415 \mathrm{kV}, 45 \mathrm{kVA}$ $\mathrm{MV} / \mathrm{LV}$ transformer and represents one community with 38 households. The network characteristics is available in $[38,39]$ and is shown in Fig. 3.

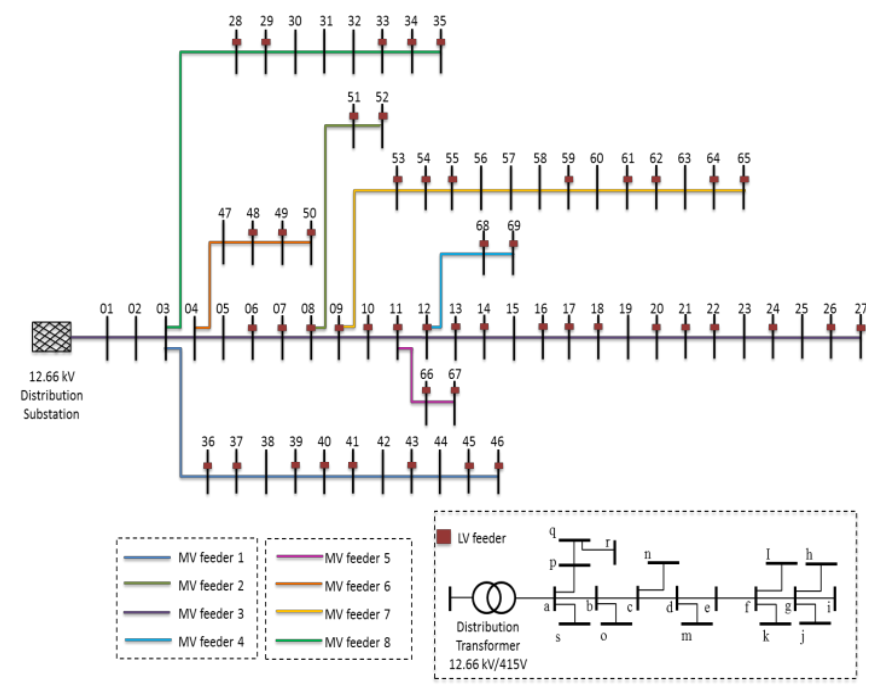

Fig. 3. One-line diagram of the test network

In order to identify the households' load profiles, the dataset of the Ireland Electricity Smart Metering Trials [40] is used. The dataset comprise 4232 Irish households with half hourly meter readings resolution.

The maximum DR potential $\left(\mathbf{l}_{\mathbf{h}, \mathbf{t}}^{\mathbf{L D}, \mathbf{m a x}}\right)$ and the attitude towards DR participation $\left(\mathbf{A}_{\mathbf{h}}\right)$ for different cluster of consumers is obtained from $[4,5]$. For each HA belongs to a specific cluster, a synthetic load profile $\left(\mathbf{l}_{\mathbf{c}, \mathbf{h}, \mathbf{t}}\right)$ is then created around the centroid of that cluster. It is assumed that HAs who participate in LCDR will always meet the DCL allocated to them. A typical PV model in July, as representor of the same month which the dataset is chosen, is considered for households with on-site generation. The power output of PV is available in [8].

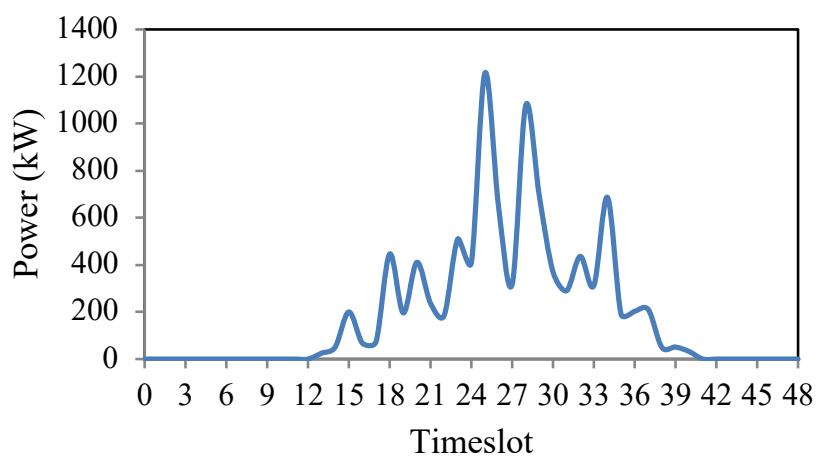

Fig. 4. PV output power

Four different scenarios are considered in this research. The modelling and simulation is implemented for each case study and for a typical day with 48 timeslots in MATLAB. Scenario 1 can be considered as a scenario without DR and the rest as scenarios with DR. The scenarios are described in the following. 
Scenario 1: This scenario is considered as the reference benchmark where DR is not applied in the test network.

Scenario 2: HAs with PV attempts to maximise their power consumption through local generation. It is assumed that all HAs have PV to investigate the maximum effect of PV on total demand reduction at the community level.

Scenario 3: After implementing scenario 2, in this scenario, HAs who still have demand that is need to be supplied from the external grid provide DR from further reduction in their total consumption (load shedding).

Scenario 4: The purchasing of extra available generation in the community is modelled in this scenario. Hence, the required demand in this scenario is calculated after implementing scenario 2 and 3.

\section{SIMULATION RESULTS}

In order to evaluate the feasibility and effectiveness of the proposed framework, the methodology has been firstly applied for one community. This has been further extended to several communities with different features and the results compared.

In scenario 2 and 3 , the contributors are incentivised per $\mathrm{kW}$ power reduction. In contrast, in the last scenario, feed-in-tariff is paid to consumer for each $\mathrm{kW}$ power generation. It is assumed that incentives are determined same for all HAs. Also, the satisfaction factor $\left(\boldsymbol{\delta}_{\mathbf{h}}\right)$ as well as the available DR from each HA is maximum. It is worth to note that in scenario 3 , the DCL assigned to each HA is its maximum load curtailment. The main aim of this paper is to study the benefits and effects of local energy community engagement in managing demandsupply equilibrium. Fig. 5 shows the aggregated load profiles of all HAs within the community for all scenarios.

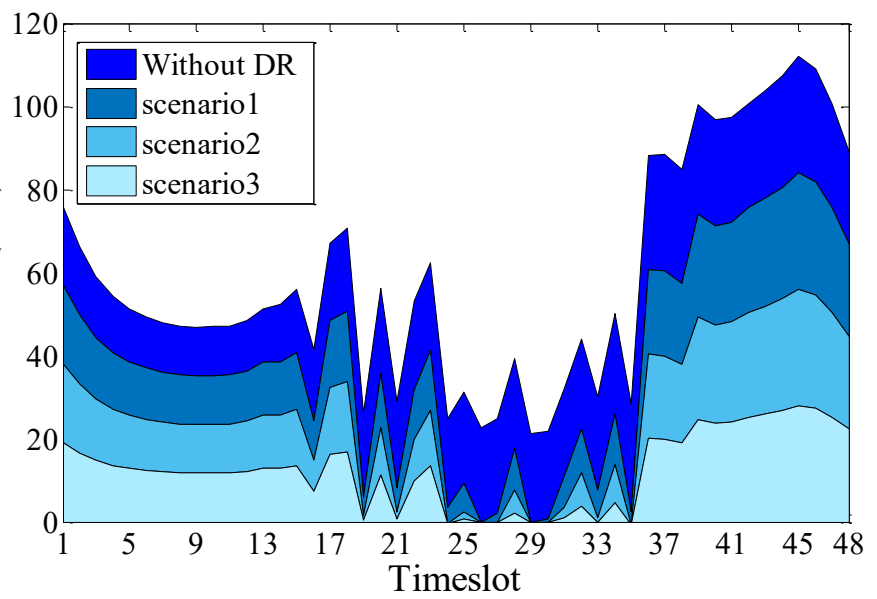

Fig. 5. The aggregated load profiles of all households in one community for all scenarios in LCDR

As can be seen, the load profiles have similar pattern in all scenarios. During timeslots which no PV generation is available, the amount of demand reduction in scenarios 2,3 and 4 are equal. That was expected as the only load responsiveness is from load shedding at each household. At scenarios with DR, the community experienced an improvement to its independency to the power grid. Implementing all possible DR opportunities (scenario 4), the minimum load profile during the simulation day have been achieved.

Fig. 6 presents the percentage of maximum load reduction resulting from simulating DR. These are $25.68 \%, 67.8 \%$, and $26.3 \%$ for scenarios 2,3 and 4 respectively.

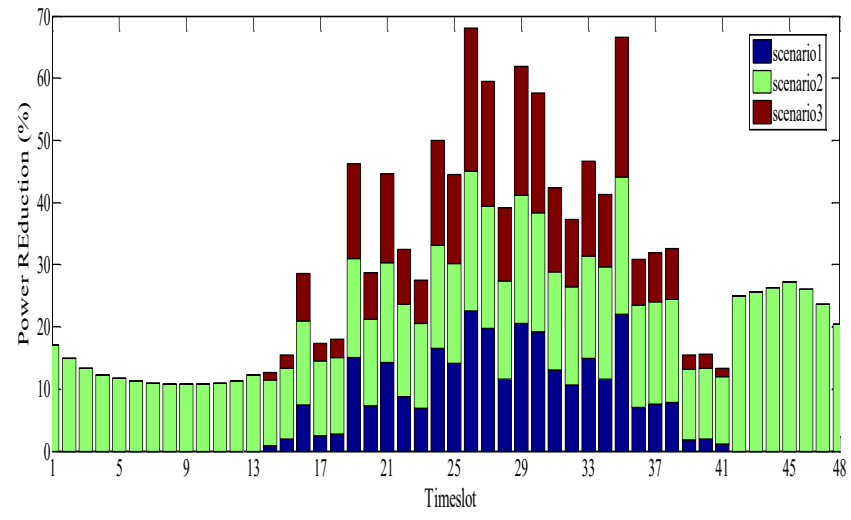

Fig. 6. Percentage of the total demand curtailment of one community for all scenarios with DR in LCDR

Since the scenarios 2 and 4 are dependent on the solar generation, the load reduction is only possible during the sun time. Hence, the maximum DR has been achieved at timeslot 26 where the PV power output was maximum. On the other hand and as an alternative, in scenario 3, DR can be provided during all day. However, the amount of load reduction over time is dependent on the load profile and accordingly the DR potential in each household.

The impact of local community and the proposed methodology on the voltage profile of the feeder is shown in fig. 7. A significant increment in the voltage profile for daytime, when PV generation is available, is observed. Moreover, the provision DR from implementing scenario 3, improves the voltage at all timeslots.

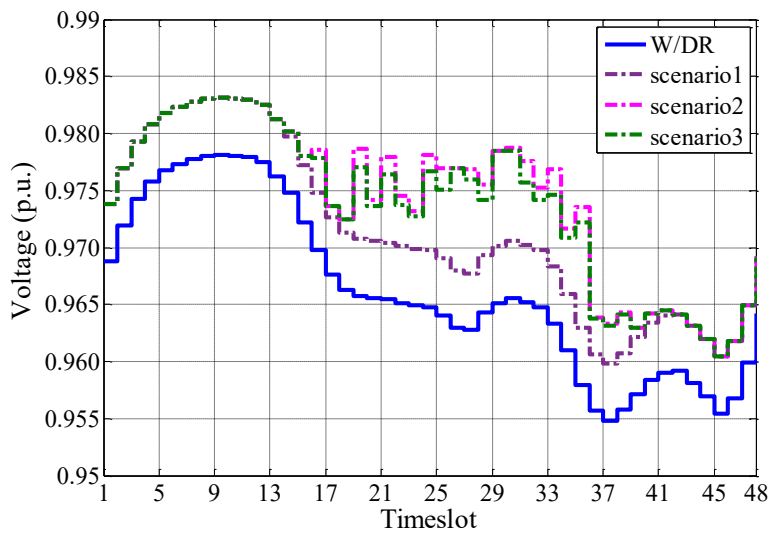

Fig. 7. Voltage Profile of the selected feeder in all scenarios

\section{ANALYSIS OF RESULTS}

In the aim of assessing the key features that can effect on consumer's consumption, several communities are considered with different setting parameters. These attributes are consumer's participation rates and financial motivations, as well as PV penetration rates within each community. The last 
one refers to the PV ownership ratio of households in one energy community

Firstly, the effect of PV penetration and participation rate on the total demand curtailment is studied. Considering different participation rates, the PV penetration ratio in each community is set differently. The percentage of consumer's participation in DR is being changed from $0 \%$ to $100 \%$ with $10 \%$ step. In each step, four PV ownership rates including $20 \%, 40 \%, 60 \%$ and $100 \%$ are considered. The simulation results are drawn in Fig. 8.

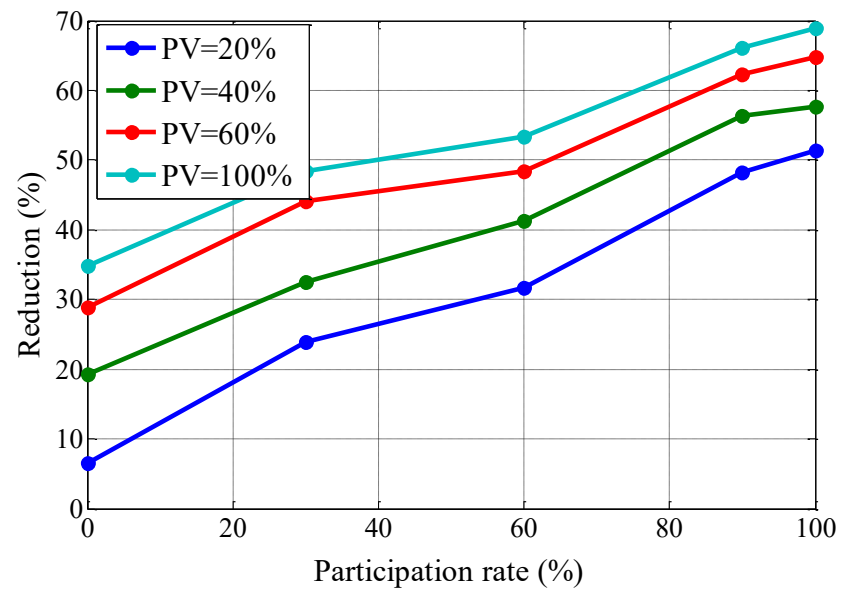

Fig. 8. Effect of consumer participation and PV penetration rates on the overall demand curtailment in the energy community

A similar incremental trend is observed in the relation between power reduction and depth of PV penetrations. At PV penetration of $100 \%$, where all HAs are equipped with PV, the maximum demand reduction has been achieved and it was $69 \%$. Even with participation rate of $0 \%$, a small percentage of DR has been resulted from PV generation. For instance, at PV penetration of $20 \%$ with $0 \%$ participation rate, the demand reduction was $6.5 \%$. It can be explained as scenario 3 includes both local generation and available load curtailment. Participation rate is only considered for HAs involving in the latter.

Secondly, the impact of financial motivation on consumer's participation is investigated. In this respect, 11 communities have been considered. A UK pilot study in [226] is used to determine the incentive rates. The pilot trialled and studied the households' peak electricity demand reduction. The financial motivation has been varied from $0 \%$ to $100 \%$ with a $10 \%$ incremental step. Each community has different incentive value starting from 6 pence/kWh for the first community to 15 pence $/ \mathrm{kWh}$ for the last one. The simulation results are depicted in Fig. 9. As it was expected, it can be seen that there is a direct and incremental relation between the growths of financial motivation with the participation rate. The last community where the highest incentive rate is defined for, has experienced the maximum percentage of consumers' participate and together with the $100 \%$ financial motivation.

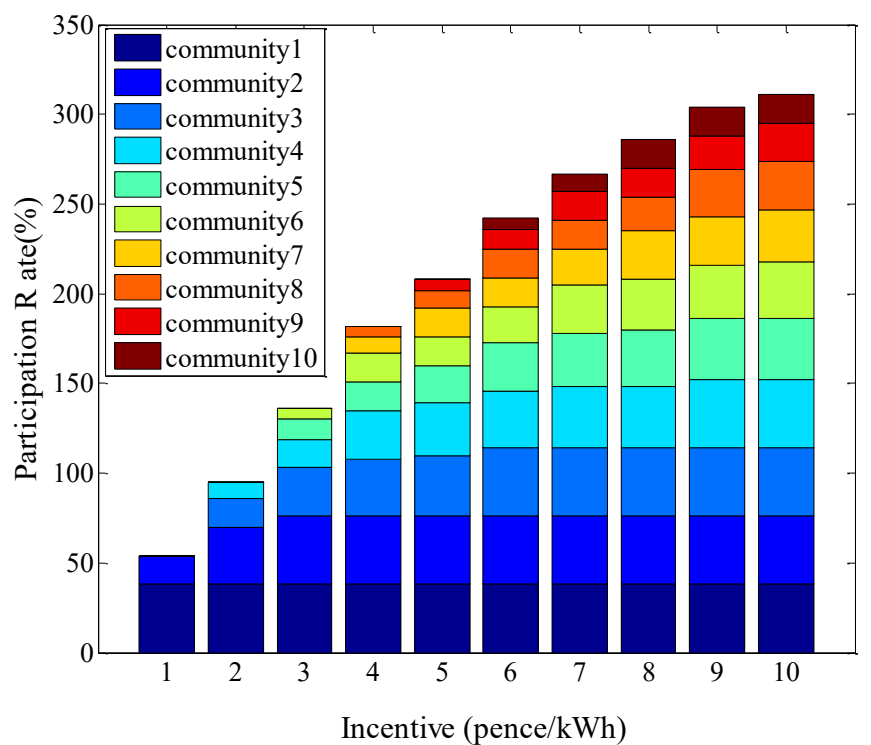

Fig. 9. The impact of financial motivation on households' participation in LCDR

As explained previously, the community with the highest DR provision is chosen at community reward scheme. The DR measurement in each community is based on the demand reduction in comparison of its baseline load. The allocated reward is shared among all participants within the energy community. This game scheme can enhance the household's motivation in engagement in LCDR.

All HAs within one local community collaborates together to meet the goal of the community. This shows the advantage of a MAS framework in enabling the implementation of DR from the aggregation of small residential responsiveness loads.

Regarding to fig. 9, the sensitivity of communities to the incentive rates in some communities is less. This shows that the participation rates at households need to be maximum. However, due to distinctive potential of flexible loads and available generation among households, they are not always comparable at the community level.

\section{CONCLUSION AND FUTURE RESEARCH}

An advanced DR scheme, LCDR, is proposed and implemented in this paper. Several household agents are connected to one specific LCAA and work together to reduce the total energy in that community. They are getting motivated in two ways: by receiving incentive for each $\mathrm{kW}$ demand reduction or winning the community-reward game. In the latter, the winner is the best community with highest demand reduction where the reward us shared among partakers.

Three different DR scenarios were defined (scenario 2-4) and studied along with one reference benchmark (scenario 1). In scenario 2 and 3, HAs attempts to provide their energy consumption from the maximum PV output and from reducing their energy uses respectively. In the last scenario, LCAA maximises the community independency to the power grid by trading-off the extra available generation among HAs. The simulation results for one community with 38 households considering the maximum participation rate, PV penetration and financial motivation showed $25.68 \%, 67.8 \%$ and $26.3 \%$ 
load reduction for scenario 2, 3 and 4 respectively. Moreover, the relation between the consumer's key attributes on the total demand reduction follow an incremental linear relation.

The DR implementation is under real-time environment where households decide about their contribution in loadreduction scheme individually at each time interval. Hence, the level of households' satisfaction can be maximised while the DR can contribute in mitigation the network constraints.

\section{REFERENCES}

[1] B. Hayes, I. Hernando-Gil, A. Collin, G. Harrison, and S. Djokić, "Optimal power flow for maximizing network benefits from demandside management," IEEE Transactions on Power Systems, vol. 29, no. 4, pp. 1739-1747, Jul. 2014.

[2] "The future of demand response in electricity distribution," Accenture, 2016. Available:

https://www.accenture.com/t20170406T202722Z__w_/usen/_acnmedia/PDF-48/Accenture_Future-Demand-Response-POV.pdf

[3] S. CHEN, and C.C. LIU, "From demand response to transactive energy: state of the art," Journal of Modern Power System and Clean Energy, vol. 5, no. 1, pp. 10-19, 2017.

[4] S. Davarzani, I. Pisica and G. Taylor, "Development of a Novel MultiAgent System for Residential Voltage Control Using Demand Response based on Customer Behaviour," IEEE ISGT Europe, Torino, Italy, 2629 Sept.2017.

[5] S. Davarzani, I. Pisica, L. Lipan,, "Novel model for defining electricity tariffs using residential load profile characterisation," International Journal of Renewable Energy Technology, 13 Feb. 2018 (Accepted).

[6] S. Deilami, A. S. Masoum, P. S.Moses, and M. A. S. Masoum, "Realtime coordination of plug-in electric vehicle charging in smart grids to minimize power losses and improve voltage profile," IEEE Trans. Smart Grid, vol. 2, no. 3, pp. 456-467, Sep. 2011.

[7] D. Zhang, Z. Fu, and L. Zhang, "An improved TS algorithm for lossminimum reconfiguration in large-scale distribution systems," Electric Power Systems Research, vol. 77, pp. 685-694, 2007.

[8] "Data from the Commission for Energy Regulation (CER) - smart metering project," Irish Social Science Data Archive [Online]. Available:

http://www.ucd.ie/issda/data/commissionforenergyregulationcer/., [Accessed 2702 2017].

[9] Newquay Weather Station, [Online]. Available: http://www.newquayweather.com/wxsolarpvlog.php. [Accessed 2004 2018].

[10] Elexon, "Load Profiles and their use in Electricity Settlement," Available:https://www.elexon.co.uk/knowledgebase/profile-classes, Last seen: Jul. 2015.

[11] G. Grigoras, G. Cartina, E.C. Bobric and C. Barbulescu, "Missing Data Treatment of the Load Profiles in Distribution," IEEE Bucharest Power Tech Conference, Bucharest, Romania, 2009.

[12] A. Mutanen, M. Ruska, S. Repo, P. Jarventausta, "Customer classification and load profiling method for distribution systems," IEEE Transaction on Power Delivery, vol. 26.3, Jul. 2011. 